\title{
HRM practices and innovation: an empirical systematic review
}

\author{
Nasser Fathi Easa
}

Faculty of Business Administration, Beirut Arab University, Beirut, Lebanon and Faculty of Commerce, Alexandria University, Alexandria, Egypt, and

\author{
Haitham El Orra \\ Faculty of Business Administration, Beirut Arab University, Beirut, Lebanon
}
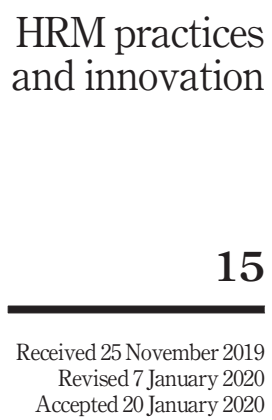

\begin{abstract}
Purpose - The relationship between human resource management practices (HRMP) and innovation has been described as a black box, where a lot still needs to be investigated. Thus, the aim of this paper is to investigate the nature of the link that exists between HRMP and innovation in both public and private organizations. To do so, theoretical underpinnings and existence of a mediating or a moderating mechanism is inspected.

Design/methodology/approach - Based on an empirical systematic review of research conducted between 2010 and 2018, content analysis has been conducted for 31 peer-reviewed articles in the English language.

Findings - Inspecting the nature of relations existed in the chosen articles, interesting findings are addressed relative to the nature of the human resource management systems (HRMS) used, practices encompassed and their different utility. HRMS has been shown to be associated with product innovation yet more evidence is needed for supporting process innovation.

Practical implications - The HRMS/HRMP and innovation relationship is inspected, important practices that would guide managers to induce innovation are highlighted. Usage of multiple HRMS and contingency in constructing such systems is indicated.

Originality/value - Contribution to comprehend the black box and areas for future research has been offered.
\end{abstract}

Keywords Innovation, Systematic review, HRM practices, HRM systems

Paper type Research paper

\section{Introduction}

Human resource management practices (HRMP) have been gaining an increased attention especially in the fields of economics of the organization, strategic management and human resource management (HRM) (Laursen and Foss, 2003). Moreover, the past two decades were characterized by noticeable progress in researching human resource management systems (HRMS) (Wei and Lau, 2010). HRMS and innovation relationship in firms is growing as many researchers inspected this area (Vogus and Willbourne, 2003; Beugelsdijk, 2008; De Winne and Sels, 2010; Ma Prieto and Pilar Pérez-Santana, 2014; Chen et al., 2018).

(C) Nasser Fathi Easa and Hitham El Orra. Published in International Journal of Disruptive Innovation in Government. Published by Emerald Publishing Limited. This article is published under the Creative Commons Attribution (CC BY 4.0) license. Anyone may reproduce, distribute, translate and create derivative works of this article (for both commercial and non-commercial purposes), subject to full attribution to the original publication and authors. The full terms of this license may be seen at http://creativecommons.org/licences/by/4.0/legalcode

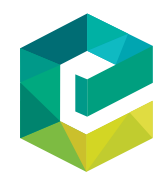

International Journal of Disruptive Innovation in Government Vol. 1 No. 1, 2021 pp. $15-35$ 2516-4392 DOI 10.1108/IJDIG-11-2019-0005 


\section{IJDIG 1,1}

This growing interest is because of the continuous search for having a competitive advantage in a highly turbulent environment (Jimenez-Jimenez and Sanz-Valle, 2008; Shipton et al., 2005).

Innovation can be promoted through proper management of people (Shipton et al., 2005). Moreover, firms intending to innovate consider HRMP as a precious resource (Beugelsdijk, 2008). Furthermore, human capital when leveraged organizational expertizes are developed, thus innovation would emerge as new products and services (Chen and Huang, 2009). Several ways can be adopted to inspect the HRMP and outcomes linkage. However, the current approach is the following: complementarities or bundle of practices or individual practice in isolation (Wright and Boswell, 2002).

This study seeks to contribute for the comprehension of the HRM and innovation relationship. It has been identified as a black box by several researchers including (Beugelsdijk, 2008; Laursen and Foss, 2003; Messersmith and Guthrie, 2011). Thus, this study tries to inspect the way by which HRM and innovation are linked. Moreover, if there is a need for a mediating or moderating mechanism to understand such a relation.

In what follows the paper is arranged accordingly, first the methodology of the papers selection is explained. Next, the papers are summarized according to the way that HRMP or human resources systems affect innovation. Then, the existence of mediators and moderators as an explaining mechanism is examined. Eventually, practical implication, directions for future research and conclusion of the study are presented.

\section{Methodology of the review}

The 31 studies analyzed were published from January 2003 to December 2018 in 18 Journals (Table I). The list is mainly based on high ranking journals with a proven history and impact in the HRM research. The database used includes the following: Academy of Management, Sage Journals, Wiley online library, Taylor and Francis online, science direct, Oxford Academic and Emerald insight.

As a start, the research objective is defined and the conceptual boundaries are set. HRMP and innovation are conceptualized according to the following dimensions: HRMP (bundle/ single); characteristics of HRMP; definitions of innovation; dimensions of innovation; the existence of a moderator-mediator; outcomes of HRMP in an indication for innovation in all its forms. Moreover, the focus was on the firm level.

\section{Data collection method}

The database on HRMP and innovation in firms was built through specific inclusion criteria. Figure 1 resembles the selection process adopted; as a start, the AJG Academic journal guide for journal ranking was examined to select, which journals to include in the study. Second, the main concentration was on HRM and employment journals. Moreover, the secondary and supportive source of data were, namely, general management, organization studies, innovation, psychology, economics, international business and hospitality. Third, titles, abstracts and keywords are inspected within the selected journals using the following key terms: "HRMP;" innovation and firm.

Studies identified counted 3,118, however, those that were not listed in AJG (2018) academic guide for journal ranking was dropped. Moreover, books, reviews, case studies, introductions, editorials, proceedings and abstracts were also excluded; only empirical articles were taken into consideration. Studies that had zero citations, except those published in 2018 was dropped. Next, all articles published before 2010 and included in the study had at least 60 citations. Also, research papers having the workplace and the organization as their unit of study was dropped, leaving us with 29 articles. However, 
Human Resource Management Journals

Human Resource Management

Human Resource Management Journal

The International Journal of Human Resource Management

International Journal of Manpower

Employee Relations

Personnel Review

General Management/Organization Studies/Innovation Journals

Academy of Management Journal

Journal of Management

Journal of Management Studies

Journal of Business Research

Organization Studies

Human Relations

Journal of product Innovation Management

Creativity and Innovation Management

Psychology/Economics/ International Business/Hospitality

Journal of Organizational Behavior

Cambridge Journal of Economics

International Business Review

International Journal of Hospitality Management

Total
HRM practices and innovation

Article count $\quad(\%) \quad$ grade (AJG, 2018)

\section{Grade 4}

Grade 4

Grade 3

Grade 2

Grade 2

Grade 2

Grade 4*

Grade 4*

Grade 4

Grade 3

Grade 4

Grade 4

Grade 4

Grade 2

Grade 4

Grade 3

Grade 3

Grade 3
Table I.

List of journals and ranking

studies that used companies and firms interchangeably were adopted, which gave us an addition of 2 articles, leaving us with 31 articles.

\section{Human resource management practices and innovation in firm research}

The HRMP and innovation relationship in firms is tested in a variety of contexts in this systematic review. This review declares that HRMP and innovation in firms are being empirically explored and has an international appeal as different countries are encompassed.

\section{Distribution of studies}

Laursen and Foss (2003) declared that the attention to HRMP and innovation in firms goes back to the late nineties. Their paper is considered to be essential in inspecting the relationship between HRMP and innovation in firms. Thus, the current study took the year 2003 as a starting point to inspect the previously mentioned relationship. The variance of interest in such a relationship is quite noticed since 2010 (Figure 1). The years 2010-2018 accounts for the most empirical output in the field of study $(n=22)$. Moreover, the main journals in the study are the following: Human Resource Management (6 articles), The International Journal of Human Resource Management (6 articles), International Journal of Manpower (2 articles), Human Resource Management Journal (2 articles) and Journal of Management (2 articles). Two third of the articles were published in human resource management journals $(n=20)$.

Furthermore, the quality of the journals used was distributed accordingly. Approximately 10 per cent of the studies used were published in Grade 4* journals; 41 per 


\section{IJDIG \\ 1,1}

18

Figure 1.

Chart of articles selection method
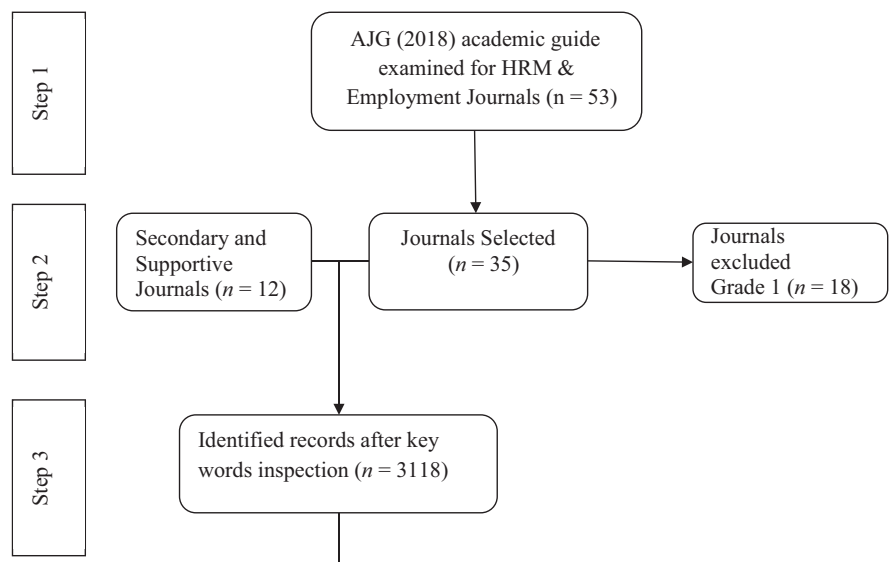

Identified records after key

words inspection $(n=3118)$
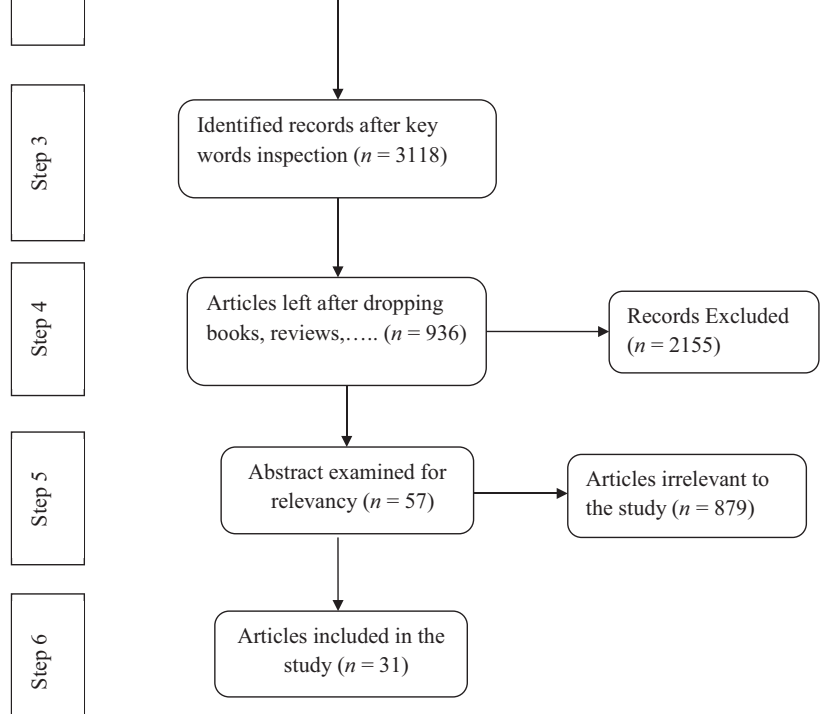

cent were published in Grade 4 journals; 31 per cent were published in Grade 3 journals and the remaining 18 per cent were published in Grade 2 journals.

In addition, articles revealed a spread over 15 countries, namely, China and Spain dominated the articles count, eight articles for China and seven for Spain, the USA, the UK and Korea counted for two articles each. The rest of the articles were distributed along 10 countries mainly located in Europe. Thus, suggesting an opportunity for a globalized research, if supported with more samples from different countries. Moreover, what has been noticed supports the claim that China is heading to be the world's innovator (Casey and Koleski, 2011).

\section{Theoretical perspective}

To identify the theories used, Nolan and Garavan (2016) approach is adopted, thus, relying on "what theory is not by" (Sutton and Staw, 1995). Human resources theories were spotted such as, namely, human capital theory is used to explain the relationship between innovations and organizational culture; social context theory to explain the organizational culture and employee behavior relationship (Lau and Ngo, 2004). Moreover, learning theories is noticed, for example: organizational learning theory used to explain the impact of knowledge enhanced on innovation (Chang et al., 2013; Shipton et al., 2005); Upper echelon 
theory was used to stress the importance of managers' knowledge in evoking innovation (De Winne and Sels, 2010) (Figure 2).

Furthermore, the resource-based view (RBV) usage is prominent either in isolation or in complementarities. As for the first, RBV has been deployed to explain, namely, the influence of competitive advantage, the support of the knowledge, skill and abilities and intellectual capital on innovation, respectively (Jimenez-Jimenez and Sanz-Valle, 2008; Lopez-Cabrales et al., 2009; Donate et al., 2016). While for the later, RBV has been combined with creativity theory as an antecedent for creativity, thus leading to innovation (Beugelsdijk, 2008); institutional theory to grab a better understanding of the context as RBV alone fails to do so (Cooke and Saini, 2010); and dynamic capabilities (DC) to enhance innovative performance (Messersmith and Guthrie, 2010).

In addition, the social exchange theory was used in combination with equity theory. Both theories support the claim that employees value the relationship with organization relative to incentives and rewards received (Jiang et al., 2012). Thus, when employees are valued, they reciprocate the organization with an extra effort and novelty in doing things. Also, the job characteristics theory is used in combination with social cognitive theory to the support the impact of change-oriented HRMS (Lee et al., 2016). Job characteristics theory increases self-responsibility toward the change and social cognitive theory enhances self-efficacy. Also, organizational support theory was used to explain how managerial support and HRMP would enhance R\&D activities, and thus innovation (Stock et al., 2014). Besides, the presence of knowledge-based view not to be ignored in explaining the importance of knowledge management's impact on innovation (Andreeva et al., 2017; Chen and Huang, 2009).

Finally, the usage of the ability, motivation, opportunity (AMO) framework developed by Bailey (1993) is noticed to be prominent after the year 2014. HRMP are declared to be channeled through, the ability enhancement, motivation and opportunity given for employees (Ma Prieto and Pilar Pérez-Santana, 2014; Fu et al., 2015; Lee et al., 2016; DiazFernandez et al., 2017).

\section{Methodology}

To analyze the methodology characteristics three aspects have been examined, namely, the industry, the unit of analysis and methods adopted.

\section{Industry}

The main industry that has been noticed in the chosen articles is the manufacturing sector as it is present in 11 articles. The information and communication technology, is present in 6 papers. The food and beverage, automotive and service industry is present in four research studies. The wholesale trade, computer software industry, electronics, chemical industry, construction and hotel industry was noticed to be covered in 3 articles. The catering,
HRM practices
and innovation

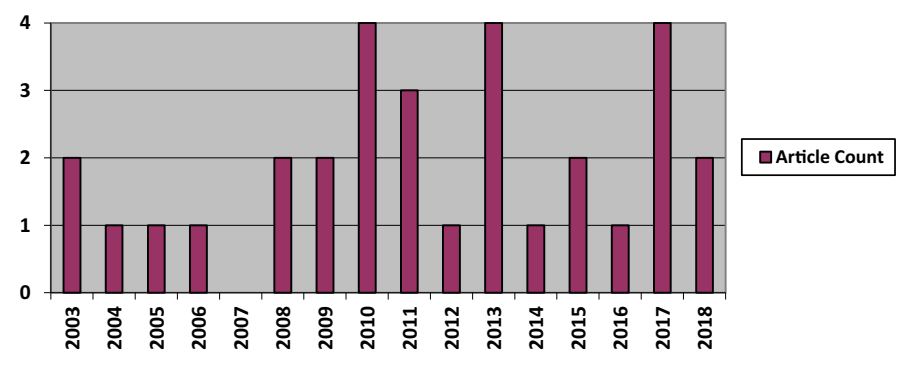

Figure 2.

Distribution of empirical HRMP and innovation publications 
$\underset{1,1}{\text { IJDIG }}$

transportation, financial service and textile industry is allocated in two papers. The health and personal service, retail trade, internet and added values services, biotechnology and pharmaceutics and metallurgy industry were inspected in one article each. What is noticed of what been mentioned above that the focus is on the manufacturing industry and there are still some industries to be covered such as oil, education and advertising industries. However, what is interesting that one of the articles excluded the agriculture sector. This may raise some questions and would constitute an opportunity for future research.

\section{Unit of analysis}

The individual is the essential unit of investigation of HRMP and innovation in firm research. The human resource director (HRD) was exclusively the unit of analysis in five articles, the Chief Executive Officer (CEO) in one article and the manager. Top executives including (CEO, general manager) were the unit of analysis in three papers, the CEO and the $\mathrm{HRD}$ in two papers, the CEO, production manager and HRD in one paper. Moreover, the CEO, middle-level managers and local stake holders was the unit of analysis in one paper, the CEO, HRD and financial controller in one article. Furthermore, The HRD and owner/ manager (entrepreneur), was the unit of analysis in two research studies, the HRD and technology manager in one paper, the $\mathrm{HRD}$, operational manager and employee in one article, the HRD, strategic director, production manager and the employee in one paper. Also, the senior, middle and junior managers were the unit of analysis in one paper, the senior executives in one article and the marketing manager and R\&D manager in one research. As noticed, almost all of papers have focused on either top or middle management to represent the firm without giving an attention to the lower level of employees. Thus, supporting the claim that employeès opinion and reaction to HR practices is usually not addressed in HRM literature (Nolan and Garavan, 2016).

\section{Methods used}

The empirical systematic literature review revealed some aspects about the methodological trends used. In total, 27 studies used questioners or surveys (interchangeably) for data collection, only two of them were longitudinal, while the rest were cross-sectional. Moreover, two studies used a mixed approach of a questioner and an interview. Furthermore, the rest two articles have adopted an interview approach with a longitudinal nature, thus a total of four articles having a longitudinal approach.

\section{Content analysis}

The content analysis of HRMP and innovation in firms focused on the following aspects: HRMP (bundle/single); existence of a moderating or a mediating variable, namely, characteristics of HRMS; definitions of innovation; outcomes of HRMP in an indication for innovation in all its forms.

\section{Human resource management systems or human resource management practices}

Lado and Wilson (1994) defined an HRMS as "a set of distinct but interrelated activities, functions and processes that are directed at attracting, developing and maintaining or disposing of a firm's human resources." Thus, indicating for the complementary and interrelated nature of the practices formulating an HRMS that imposes a competitive advantage for the firm. Moreover, high-performance work systems (HPWS) in accordance with what have been mentioned earlier is defined as "a system of HRMP designed to 
enhance employees' skills, commitment and productivity in such a way that employees become a source of sustainable competitive advantage" (Pfeffer and Jeffrey, 1998).

Moreover, the majority of researchers have adopted HMR practices in isolation to inspect its impact on performance (Wright and Boswell, 2002). However, there is a call for adopting sophisticated HRMS to induce product and technological innovation (Shipton et al., 2005). HRMP when adopted as a system, is expected to evoke innovation as noticed in many research studies, for example: De Winne and Sels (2010), Lopez-Cabrales et al. (2009) and many others.

The notion of complementarities is essential for HRMP to induce innovation (Laursen and Foss, 2003). However, it has been found that isolated HRMP induce innovation to a certain extent. However, their interactive impact will be more significant (Beugelsdijk, 2008; Shipton et al., 2006). Furthermore, the impact of a single practice of HRM on a firm 's performance is not beneficial (Lau and Ngo, 2004). Additionally, Jimenez-Jemenez and SanzValle (2005) in their study announced a lack of support for the claim that HRMP in isolation would induce innovation.

Moreover, the aspect of integration and fit is highlighted as; HRM system alone might not induce innovation unless accompanied by an organizational culture that supports innovation. Furthermore, the existence of an innovative strategy accompanied by the HRMP is essential for firm innovation (Jimenez-Jemenez and Sanz-Valle, 2005). On the other hand, the alignment of HRMP toward the same goal may have a negative effect (Andreeva et al., 2017).

In summary, papers that used HRMP as a bundle was $(n=26)$; in isolation $(n=4)$; a mixture of a bundle and isolation $(n=1)$. It is noticed that most researchers agree on the notion of the bundle, however, lack of agreement is noticed relative to the type of practices to integrate in the system (Jimenez-Jemenez and Sanz-Valle, 2005).

\section{Human resource management systems characteristics}

A variety of HRMS is used in literature with different HRMP and purposes. HRMS are categorized according to their purpose, namely, innovation-oriented encompassing practices that help build an innovative culture (Lau and Ngo, 2004); a learning supportive (De SaaPerez and Díaz-Díaz, 2010; Laursen and Foss, 2003; Shipton et al., 2005; Shipton et al., 2006); an exploration and behavior fit to strategy (Cooke and Saini, 2010); flexibility and adaptive capability-oriented system to face the rapid environmental changes (Chang et al., 2013; Jimenez-Jimenez and Sanz-Valle, 2008; Martínez-Sánchez et al., 2011; Wei and Lau, 2010); a system that allow firms to evoke knowledge and build expertize (Andreeva et al., 2017; Chen and Huang, 2009; De Winne and Sels, 2010; Lopez-Cabaralez et al., 2009; Sung and Choi, 2018); high performance work systems used to motivate and build human and social capital (Fu et al., 2015; Donate et al., 2016; Messersmith and Guthrie, 2010); commitment oriented that establish social relations and evokes employee commitment toward the organization and risk taking (Ceylan, 2013; Chen et al., 2018; Neives and Osorio, 2017; Zhou et al., 2013); a collaboration HRMS that helps in the development of equality relationship (Zhou et al., 2013); high involvement work practices that induce management coworkers support (Ma Prieto and Pérez-Santana, 2014); a change oriented that impact employee psychological status such as self-efficacy and responsibility to change (Lee et al., 2016); and a creativity inducing system (Liu et al., 2017).

In summary, HRMS that builds knowledge capabilities evokes flexibility and learning is highly used in research. Moreover, commitment systems are quite noticed, however, the concepts of fit, culture and collaboration need to be more research as few studies have been encountered. Additionally, the same systems encompassing different HRMP were used for different purposes. Furthermore, different systems have been used for the same purpose. 
IJDIG 1,1

Systems used for different purposes are high performance work system, high commitment human resource system. The first was used to; motivate, build human and social capital (Messersmith and Guthrie, 2010); to enhance adaptive capability (Wei and Lau, 2010); and induce innovative work behavior (Fu et al., 2015). The latter, was used to support learning (De Saa-Perez and Díaz-Díaz, 2010); enhance innovative capability (Zhou et al., 2013) and innovative behavior, evoke organizational commitment and employee risk-taking Chen et al. (2018) and alignment of strategy (Cooke and Saini, 2010). This supports the notion that HRMS are used interchangeably especially HPWS, high involvement work system (HIWS) and high commitment work systems (HCWS) (Chen et al., 2018).

\section{Human resource management practices in isolation}

Utilization of HRMP in isolation is quite noticed and adopted in recent research studies. The practices used can be categorized according to their purpose of usage. Lau and Ngo (2004) used three practices directed toward mindfulness; Jiang et al. (2012) adopted eight practices to evoke employee creativity; Stock et al. (2014) used four innovation-oriented practices; and Diaz-Fernandez et al. (2017) incorporated four practices aiming at enhancing employee abilities, motivation and opportunity to innovate.

\section{Innovation by definition}

Different definitions of innovation have been encountered, thus a trial has been conducted to set a certain trend for the definitions adopted. The definition by West and Far, used by Jiang et al. (2012), Shipton et al. (2005) and Shipton et al. (2006). It captures the deliberate behavior directed toward new (products, ideas and processes), that is new to the adopting unit and beneficial for the organization and society. Moreover, its usage has been noticed to be mainly for the technological products and processes.

Next, the prominent author relied upon in defining innovation was Damanpour, as there has been three definitions established during the following years 1989, 1991 and 1998. The articles are developed by: Diaz-Fernandez et al. (2017), Ceylan (2013), Chang et al. (2011), Chen and Huang (2009), Fu et al. (2015), Jemenez-Jemenez and Sanz Valle (2008), Wei and Lau (2010) and Zhou et al. (2013). Such definitions consider innovation as a performance outcome. Moreover, it captures the innovative strategy, product, project, process and organizational innovation. Furthermore, the measuring scale of patents and the classification of radical and incremental innovation was realized.

Additionally, innovation as newness in products, services, work and practices is addressed relying on (Rogers, 1983). In addition, innovation has been considered to be embedded in knowledge according to kogut and Zander (1992), Nonaka (1994) and Smith et al. (2005).

In summary, the definition of innovation adopted is mainly that of Damanpour, which states that, namely, "the adoption of an idea or behavior, whether a system, policy, program, device, process, product or service, that is new to the adopting organization" (Damanpour et al., 1989).

\section{Mediator or moderator}

Almost half the studies $(n=17)$ have used a mediator or a moderator as an explaining tool for the indirect linkage between HRMP and innovation in firms (Lau and Ngo, 2004 also Wei and Lau, 2010). The mediators used are as follows: Organizational culture, knowledge management capacity, unique knowledge, valuable knowledge, adaptive capability, innovation-oriented strategy, employee creativity, cross-functional research and development, absorptive capacity, innovative work behavior, human and social capital, firm ownership and middle managers innovative behavior. On the other hand, the moderators 
incorporated are, namely, environmental dynamism, strategic activities, compensation and benefits, employee creativity, work-family conflict and work climate.

In the following section, the outcomes of the articles included in the review are presented accordingly; and the HRMP and innovation relationship (direct/indirect). Moreover, the direct relationship is categorized into bundles, isolation and utilization of both approaches.

\section{Human resource management systems}

First, trying to find the best bundle of practices for product innovation in firms, Laursen and Foss (2003) adopted two systems, namely, the first composed of nine practices and the second composed of two; however, both having a learning objective. Their sample was 913 Danish firms with at least 100 employees. Results indicated that the complementarities effect between practices enhances their impact on innovation, however, only seven of the first system had a positive significant impact. Moreover, Shipton et al. (2005) examined the British context by sampling 32 firms having at least 70 employees. The system adopted is learning-oriented composed of six practices. Results indicated a significant impact on product production and technology innovation, however, no impact on the process. This notion was supported by Jiménez-Jiménez and Sanz-Valle (2008), when exploring the Spanish context, with a sample of 173 firms having more than 50 employees.

Also, De Winne and Sels (2010), with a sample of 294 startup firms in Belgium inspected the impact of HRMP as a bundle on product, process and service innovation. The systems composed of five practices directed toward knowledge creation and retention. Results indicated high positive significance between the bundle of practices and the mentioned types of innovation. In addition, De Saa-Perez and Díaz-Díaz (2010), while investigating the Canary Islands by sampling 157 firms having more than 10 employees. High commitment HRMP was used such as internal promotion, group-based performance appraisal among six practices. It was noticed the existence of a positive influence on product and process innovation, yet this influence varies relative to sectors.

Furthermore, Messermith and Gutherie (2010) handled a sample of 2018 firm in the USA having 20 to 100 employees. HPWS was adopted, it supported the emergence of product, organizational but not process innovation. Besides, Zhou et al. (2013) inspected two systems of HRMP, commitment and collaboration in the Chinese context of 125 firms having 50 employees and above. Both systems indicated a positive impact on organizational innovation, however, when implemented together, a negative interactions emerges this hindering innovation. The commitment-based system was used by Ceylan (2013), which enhanced various forms of innovation This positive impact on innovation is also reflected when studying 109 firms with 50 employees or more in Spain (Nieves and Osorio, 2017).

In summary, different usage of HRMP systems shown a positive association with product innovation, however, little evidence is provided to support the emergence of process innovation. Moreover, innovation level varies among sectors as some are influenced by specific types of system of practices. Thus, according to the sector, careful selection of practices should be adopted. Furthermore, it was noticed that when implementing two different types of systems, the impact of both systems on innovation is diminished. This is explained according to ambidexterity as there should be a balance if more than one system is adopted.

\section{Human resource management practices in isolation}

Next, Vogus and Wellborne (2003) examined the USA by a sample of 184 firms having an average of 238 employees. HRMP was used in isolation, results indicated that innovation output is strongly increased by these practices. Moreover, Beugelsdijk (2008) examined the Dutch context with a sample of 988 firms having a minimum of 5 employees. Outcomes 
$\underset{1,1}{\text { IJDIG }}$

highlighted the importance of adopting practices that stress training and incentives to induce incremental innovation such as follows: training, performance-based pay. While, for radical innovation the adopted practices should induce autonomy.

\section{Combination}

Then, Shipton et al. (2006) inspected the UK context through 22 firms having an average of 236 employees. They adopted a set of practices that evoke exploratory learning; results indicated that induction, appraisal, training and teamwork had a significant impact on product innovation yet; appraisal had no impact on technical system innovation. Moreover, contingent reward had no impact on both types of innovation, however, when combined with other practices as a system its impact becomes obvious. In addition, the combined influence had a stronger impact on technical innovation.

Moreover, Chang et al. (2011) when adopting selection and training practices in isolation both had a positive impact on incremental and radical innovation. However, the joint adoption had a negative impact on incremental innovation. Thus, a proper identification of practices so that, they won' $t$ impact each other negatively. Besides, Andreeva et al. (2017) adopted 3 knowledge-oriented practices to inspect jointly and separately in 259 companies with at least 100 employees in Finland. The separate impact of rewards and appraisals was positive on incremental innovation, however, no interaction impact. While, for radical innovation rewards had a positive impact while the interactive impact was negative. This supports the notion of careful selection when combing practices.

In summary, various HRMP have been examined if being used would enhance innovation, surprisingly most studies revealed that single practices would evoke innovation. However, when combined with each other innovation will be hindered. Thus, contradicting what has been mentioned above relative to the impact of bundles of HRMP on innovation.

\section{Mediators and moderators}

Finally, the existence of a mediating or moderation mechanism to explain the HRMP and innovation linkage is noticed. Lau and Ngo (2004) used innovation-oriented HRMP as a bundle in 332 firms having more than 50 employees in Hong Kong. The system used to create cross-functional teams that support change. It had a positive impact on innovation through the organizational culture. Moreover, knowledge management capacity as a moderator was adopted by Chen and Huang (2009) while examining Taiwanese firms. Results supported the mediating impact between HRMP as a bundle and innovation (administrative and technical). Furthermore, Lopez-Cabrales et al. (2009) examined the Spanish context with a sample of 86 firms having more than 50 employees. Two types of bundles was adopted; knowledge-based and Collaborative HRMP mediated by valuable knowledge and unique knowledge respectively. Hence, both systems had no direct effect, while only collaborative HRMP has an impact on innovation mediated by unique knowledge.

In addition, partial support has been recognized when examining the HPWS and product innovation relationship mediated by adaptive capability (Wei and Lau, 2010). Also, Cooke et al. (2010) inspected the impact of high commitment work practices on product, process and customer service innovation through alignment of strategy. Strong influence has been noticed, which was explained by the adoption of practices supporting each other. Also, Jiang et al. (2012) tested the impact of HRMP in isolation on technological and organizational innovation mediated by employee creativity. All practices indicated a positive mediation, however, training and performance appraisal were not. 
Next, cross-functional R\&D was inspected as a mediator between HRMP in isolation and product program innovativeness. The test conducted in the German context with a sample of 125 firms having 50 employees and above (Stock et al., 2014). Training and rewards had a strong influence on product program innovativeness, however, recruitment had no impact. Besides, the mediating role of absorptive capacity between flexibility-oriented HRMS and incremental innovation was inspected in China. Both systems indicated a significant association with firm innovativeness, however, when implemented together the positive impact fades (Chang et al., 2013).

Then, Ma Prieto and Pilar Pérez-Santana (2014) adopted a supportive work environment as a mediator between high involvement HRMP and innovative work behavior. The study was conducted in Spain handling sample of 198 firms. Outcomes indicated that direct and the mediated relationship between HRMP targeting employee's abilities, skills and opportunities and innovative work behavior is significant. As well, Fu et al. (2015) when examining the Irish context adopted HWPS and organizational innovation relationship mediated by innovative work behavior. The sample included 120 firms and results supported the direct and the mediated relationship.

Subsequently, Donate et al. (2016) sampled 72 firms in Spain, where two systems are adopted. High profile performance systems composed of five practices and a collaborative system composed of seven practices. The relation with product and process innovation was examined through human and social capital. Results indicated that both systems positively impacted product and process innovation when mediated through human and social capital respectively. In addition, Lee et al. (2016) investigated the Korean context sampling 11 firms while adopting a change-oriented HRM system. The suggested relationship between HRM system and group innovation is through employee proactively. Primary results indicated a channeling effect of employee proactive behavior, however, no mediating effect.

As for the moderated relationship between HRMP and innovation, environmental dynamism was used by Martínez-Sánchez et al. (2011) in the Spanish context. The study encompassed two flexibility-oriented systems; internal and external numerical. Moreover, the internal system is composed by its turn from functional and numerical. Results indicated that for both direct and moderated relationship the following. The internal system with both its subsystems indicated a positive relationship with innovativeness, however, only consulting contracting firms in the external system is in positive relation.

Furthermore, Diaz-Fernandez et al. (2017) conducted a longitudinal study in the Spanish context encompassing a sample of 1,363 firms. He used four HRMP in isolation to be moderated by compensation and benefits. Results indicated that only employment security and investment in new training technologies had a significant impact on innovation as long as this relationship is moderated by high salaries. However, employment security, compensation when implemented in isolation had no impact on innovation. Moreover, the language training and training in new technologies had not impact.

Additionally, what is interesting is the existence of a mediator and a moderator in three studies encompassed in the review. First, Liu et al. (2017) investigated the Chinese context by sampling 57 firms. Two systems are adopted, the employee experienced performance HRM and employee experienced maintenance-oriented HRM. The two systems implemented with employee creativity as moderator and firm ownership as a mediator. The multilevel relationship indicated a positive impact on firm innovation. Next, Sung and Choi (2018) examined the Korean contest with a two-set of knowledge stock and flow-oriented practices. The mediators used firm knowledge flow and stock, while the moderator is the strategy. Flow and stock facilitating HRMP indicated a positive impact on firm innovation through firm knowledge flow. Moreover, the moderating effect is partial as innovation is impacted 


\section{IJDIG 1,1}

through knowledge stock. Thus there is a need for a proper implementation of high levels of firm knowledge flow if to make use of firm knowledge stock in inducing innovation.

Finally, Chen et al. (2018) inspected 113 firms in the Chinese context where a high commitment work system is used. The system impact on innovative behavior is studied through middle managers innovative behavior; this relation is moderated by work-family conflict and work climate. The managers' innovative behavior successfully mediates the relationship between HCWS and firm innovative performance. However, the direct relationship was not significant, moreover work-family conflict had a negative impact on innovative behavior. Furthermore, the combined effect of HCWS with both moderating variables indicated a positive impact on innovative behavior.

In summary, the research is rich with trials to explain the relationship between HRMP and innovation through a mechanism. However, the mediating mechanism is more popular among research, thus, what would be beneficial is search for further moderators to explain the above-mentioned relationship. In what follows managerial implications for practice are presented.

\section{Practical implications}

Important practical implications are uncovered for managers that need to acquire human resources skills and competencies, which would enhance the firm 's survival rate. First, it has been noticed that the existence of training in most of the HRMS is present and plays a vital role in inducing innovation. Lack of training might be reflected in the absence of innovation, however, presence of training would prevent employees from being square minded. Thus, managers are required to focus on human capital development and adopt practices that foster knowledge and enrich employees`skills. Fostering knowledge includes the process of acquiring and sharing information among employees. Sharing information can be motivated through a bonus system that reward combined effort rather than individual ones. Moreover, managers can promote a learning environment by having the proper infrastructure needed and through nurturing social ties. On the other hand, it was noticed that training had no impact on innovation; this case needs to be investigated closely.

Second, managers have to be aware to what practices to use in the HRMS, as some practices when combined together would negatively impact the learning process in the organization. Just as the presence of individual appraisal and pay for performance. Such a case will result in conflict, which can be resolved by careful selection and proper fit among HRMP to be included in the system. Moreover, the fit is not restricted to the practices only, as the fit should take into consideration the company strategy. Third, managers who provide a secure working environment for their employees as replacing contracts with fulltime schedules, tolerate and encourage risk-taking, will lead provoke innovation. Forth, cultural aspects should be treated carefully, as when ignored will have negative impact on innovation, as cultural changes require the adjustment of management approach.

Fifth, the importance of selecting and hiring employees with unique knowledge and high education and take the proper measures to retain talents and key persons that are considered vital. This can be done through career development, promotions, flexibility, autonomy, motivation and investment in leadership practices in a dynamic environment. Finally, managers would implement more than one HRM system, however, these systems should be implemented in synergy.

\section{Future research}

As noticed in the review the theoretical underpinning of the HRMP, innovation relationship is quite noticed. However, there is still a space to examine more theories to explain this 
relationship, for example. Trait theory can be adopted as it explains the individual-level factors, which might impact HRMS positively or negatively (Tett and Burnett, 2003).

Moreover, regarding the methodology, sampling size in most studies was limited, thus, it would be beneficial to in large it. Furthermore, the impact of the context in which the practices were implemented should have been closely inspected (Vogus and Welbourne, 2003). In addition, the sector was controlled for; however, it would of interest to inspect the type of practices that would impact each sector. Also, the longitudinal approach is scarce as noticed only four articles adopted it (Diaz-Fernandez et al., 2017; Shipton et al., 2005; Shipton et al., 2006; Sung and Choi, 2018). Hence, longitudinal studies could grab the impact of the HRMP on innovation in different time intervals. Moreover, the field lacks studies that examined the sample of investigation before and after implementing the HRMP. Finally, face to face interviews when conducted would yield more in-depth information about the field of study.

Furthermore, tow contradicting perspectives have been encountered regarding the parsimony of practices. As for the first, a call is noticed for a limited number of practices, thus inducing flexibility (Jimenez-Jemenez and Sanz-Valle, 2005). While, the latter the inclusion of enormous sets of practices is noticed (Donate et al., 2016; Martínez-Sánchez et al., 2011; Zhou et al., 2013). Moreover, substitution of practices or using alternative practices would be an area of interest to be inspected. Additionally, agreement on the type of practices that are aligned and fit is missing. Finally, the inclusion of more variables to portray the linkage between HRMP and innovation is appealing such as organizational structure, psychological contract and organizational capital.

\section{Conclusion}

The 31 empirical articles reviewed suggest some improvement toward understanding the HRMP and innovation relationship in firms. The context diversity in which the studies have been conducted reveals that the HRMP and innovation relationship is a rich field yet a lot to be discovered. Practical implication are indicated, which would act as guidance for what of practices would induce innovation if implemented. However, as noticed there no specific system to apply as firms and cultural has to be dealt with according to contingency. Moreover, it suggests some additional theories to be used for inspecting the HRMP and innovation relationship.

In addition, the study encompasses areas of strength and weaknesses, as for the first the types of journals selected are high ranking, which reflects reliability of review. While the latter, the study included only empirical articles, which can be considered a weakness, as many conceptual articles was dropped. Moreover, the studies interpreted the HRMP as a bundle in different ways, with different inclusion of practices for the same system. Furthermore, all unpublished studies, Grade 1 journals, books and abstracts were excluded.

\section{References}

Andreeva, T., Vanhala, M., Sergeeva, A., Ritala, P. and Kianto, A. (2017), "When the fit between HR practices backfires: exploring the interaction effects between rewards for and appraisal of knowledge behaviours on innovation", Human Resource Management Journal, Vol. 27 No. 2, pp. 209-227.

Bailey, T. (1993), "Organizational innovation in the apparel industry”, Industrial Relations, Vol. 32 No. 2, pp. 30-48.

Beugelsdijk, S. (2008), "Strategic human resource practices and product innovation", Organization Studies, Vol. 29 No. 6, pp. 821-847. 


\section{IJDIG 1,1}

Casey, J. and Koleski, K. (2011), Backgrounder: China's 12th Five-Year Plan, US-China Economic and Security Review Commission.

Ceylan, C. (2013), "Commitment-based HR practices, different types of innovation activities and firm innovation performance", The International Journal of Human Resource Management, Vol. 24 No. 1, pp. 208-226.

Chang, S., Gong, Y. and Shum, C. (2011), "Promoting innovation in hospitality companies through human resource management practices", International Journal of Hospitality Management, Vol. 30 No. 4, pp. 812-818.

Chang, S., Gong, Y., Way, S.A. and Jia, L. (2013), "Flexibility-oriented HRM systems, absorptive capacity, and market responsiveness and firm innovativeness", Journal of Management, Vol. 39 No. 7, pp. 1924-1951.

Chen, C.J. and Huang, J.W. (2009), "Strategic human resource practices and innovation performancethe mediating role of knowledge management capacity", Journal of Business Research, Vol. 62 No. 1, pp. 104-114.

Chen, Y., Jiang, Y.J., Tang, G. and Cooke, F.L. (2018), "High-commitment work systems and Middle managers' innovative behavior in the Chinese context: the moderating role of work-life conflicts and work climate", Human Resource Management, Vol. 57 No. 5, pp. 1317-1334.

Cooke, F.L. and Saini, D.S. (2010), "(how) does the HR strategy support an innovation oriented business strategy? an investigation of institutional context and organizational practices in Indian firms", Human Resource Management: Published in Cooperation with the School of Business Administration, the University of MI and in Alliance with the Society of Human Resources Management, Vol. 49 No. 3, pp. 377-400.

Damanpour, F., Szabat, K.A. and Evan, W.M. (1989), "The relationship between types of innovation and organizational performance", Journal of Management Studies, Vol. 26 No. 6 , pp. 587-602.

De Winne, S. and Sels, L. (2010), "Interrelationships between human capital, HRM and innovation in Belgian start-ups aiming at an innovation strategy", The International Journal of Human Resource Management, Vol. 21 No. 11, pp. 1863-1883.

Diaz-Fernandez, M., Bornay-Barrachina, M. and Lopez-Cabrales, A. (2017), "HRM practices and innovation performance: a panel-data approach", International Journal of Manpower, Vol. 38 No. 3, pp. 354-372.

De Saa-Perez, P. and Díaz-Díaz, N.L. (2010), "Human resource management and innovation in the canary islands: an ultra-peripheral region of the European Union", The International Journal of Human Resource Management, Vol. 21 No. 10, pp. 1649-1666.

Donate, M.J., Peña, I. and Sanchez de Pablo, J.D. (2016), "HRM practices for human and social capital development: effects on innovation capabilities", The International Journal of Human Resource Management, Vol. 27 No. 9, pp. 928-953.

Fu, N., Flood, P.C., Bosak, J., Morris, T. and O’Regan, P. (2015), "How do high performance work systems influence organizational innovation in professional service firms?”, Employee Relations, Vol. 37 No. 2, pp. 209-231.

Jiang, J., Wang, S. and Zhao, S. (2012), "Does HRM facilitate employee creativity and organizational innovation? A study of Chinese firms", The International Journal of Human Resource Management, Vol. 23 No. 19, pp. 4025-4047.

Jimenez-Jimenez, D. and Sanz-Valle, R. (2005), "Innovation and human resource management fit: an empirical study”, International Journal of Manpower, Vol. 26 No. 4, pp. 364-381.

Jimenez-Jimenez, D. and Sanz-Valle, R. (2008), “Could HRM support organizational innovation?”, The International Journal of Human Resource Management, Vol. 19 No. 7, pp. 1208-1221.

Kogut, B. and Zander, U. (1992), "Knowledge of the firm, combinative capabilities, and the replication of technology", Organization Science, Vol. 3 No. 3, pp. 383-397. 
Lau, C.M. and Ngo, H.Y. (2004), "The HR system, organizational culture, and product innovation", International Business Review, Vol. 13 No. 6, pp. 685-703.

Lado, A.A. and Wilson, M.C. (1994), "Human resource systems and sustained competitive advantage: a

HRM practices and innovation competency-based perspective", The Academy of Management Review, Vol. 19 No. 4, pp. 699-727.

Laursen, K. and Foss, N.J. (2003), "New human resource management practices, complementarities and the impact on innovation performance", Cambridge Journal of Economics, Vol. 27 No. 2, pp. 243-263.

Lee, H.W., Pak, J., Kim, S. and Li, L.Z. (2016), "Effects of human resource management systems on employee proactivity and group innovation", Journal of Management, p. 149206316680029.

Liu, D., Gong, Y., Zhou, J. and Huang, J.C. (2017), "Human resource systems, employee creativity, and firm innovation: the moderating role of firm ownership", Academy of Management Journal, Vol. 60 No. 3, pp. 1164-1188.

Lopez-Cabrales, A., Pérez-Luño, A. and Cabrera, R.V. (2009), "Knowledge as a mediator between HRM practices and innovative activity", Human Resource Management, Vol. 48 No. 4, pp. 485-503.

Ma Prieto, I. and Pérez-Santana, M.P. (2014), "Managing innovative work behavior: the role of human resource practices”, Personnel Review, Vol. 43 No. 2, pp. 184-208.

Martínez-Sánchez, A., Vela-Jiménez, M.J., Pérez-Pérez, M. and de-Luis-Carnicer, P. (2011), "The dynamics of labour flexibility: relationships between employment type and innovativeness", Journal of Management Studies, Vol. 48 No. 4, pp. 715-736.

Messersmith, J.G. and Guthrie, J.P. (2010), "High performance work systems in emergent organizations: implications for firm performance”, Human Resource Management, Vol. 49 No. 2, pp. 241-264.

Nieves, J. and Osorio, J. (2017), "Commitment-based HR systems and organizational outcomes in services", International Journal of Manpower, Vol. 38 No. 3, pp. 432-448.

Nolan, C.T. and Garavan, T.N. (2016), "Human resource development in SMEs: a systematic review of the literature", International Journal of Management Reviews, Vol. 18 No. 1, pp. 85-107.

Nonaka, I. (1994), "A dynamic theory of organizational knowledge creation”, Organization Science, Vol. 5 No. 1, pp. 14-37.

OECD/Eurostat (2005), "Guidelines for collecting and interpreting innovation data", available at: www. keepeek.com/Digital-Asset-Management/oecd/science-and-technology/oslomanual_9789264013100-en (accessed 8 August 2015).

Pfeffer, J. and Jeffrey, P. (1998), The Human Equation: Building Profits by Putting People First, Harvard Business Press.

Rogers, M.E. (1983), Diffusion of Innovations, The Free Press.

Shipton, H., Fay, D., West, M., Patterson, M. and Birdi, K. (2005), "Managing people to promote innovation", Creativity and Innovation Management, Vol. 14 No. 2, pp. 118-128.

Shipton, H., West, M.A., Dawson, J., Birdi, K. and Patterson, M. (2006), "HRM as a predictor of innovation", Human Resource Management Journal, Vol. 16 No. 1, pp. 3-27.

Smith, K.G., Collins, C.J. and Clark, K.D. (2005), "Existing knowledge, knowledge creation capability, and the rate of new product introduction in high-technology firms", Academy of Management Journal, Vol. 48 No. 2, pp. 346-357.

Stock, R.M., Totzauer, F. and Zacharias, N.A. (2014), "A closer look at cross-functional R\&D cooperation for innovativeness: innovation-oriented leadership and human resource practices as driving forces", Journal of Product Innovation Management, Vol. 31 No. 5, pp. 924-938.

Sutton, R.I. and Staw, B.M. (1995), "What theory is not", Administrative Science Quarterly, Vol. 40 No. 3, pp. 371-384. 
IJDIG

1,1

Sung, S.Y. and Choi, J.N. (2018), "Building knowledge stock and facilitating knowledge flow through human resource management practices toward firm innovation", Human Resource Management, Vol. 57 No. 6, pp. 1429-1442.

Tett, R.P. and Burnett, D.D. (2003), "A personality trait-based interactionist model of job performance", Journal of Applied Psychology, Vol. 88 No. 3, p. 500.

Vogus, T.J. and Welbourne, T.M. (2003), "Structuring for high reliability: HR practices and mindful processes in reliability-seeking organizations", Journal of Organizational Behavior, Vol. 24 No. 7 , pp. 877-903.

Wright, P.M. and Boswell, W.R. (2002), "Desegregating HRM: a review and synthesis of micro and macro human resource management research", Journal of Management, Vol. 28 No. 3, pp. 247-276.

Zhou, Y., Hong, Y. and Liu, J. (2013), "Internal commitment or external collaboration? The impact of human resource management systems on firm innovation and performance", Human Resource Management, Vol. 52 No. 2, pp. 263-288.

\section{Further reading}

Cano, C.P. and Cano, P.Q. (2006), "Human resources management and its impact on innovation performance in companies", International Journal of Technology Management, Vol. 35 Nos 1-4, pp. 11-28.

Chowhan, J. (2016), "Unpacking the black box: understanding the relationship between strategy, HRM practices, innovation and organizational performance”, Human Resource Management Journal, Vol. 26 No. 2, pp. 112-133.

Curado, C. (2018), "Human resource management contribution to innovation in small and medium-sized enterprises: a mixed methods approach", Creativity and Innovation Management, Vol. 27 No. 1, pp. 79-90.

Gong, Y., Law, K.S., Chang, S. and Xin, K.R. (2009), "Human resources management and firm performance: the differential role of managerial affective and continuance commitment", Journal of Applied Psychology, Vol. 94 No. 1, p. 263.

Li, Y., Wang, M., Van Jaarsveld, D.D., Lee, G.K. and Ma, D.G. (2018), "From employee-experienced highinvolvement work system to innovation: an emergence-based human resource management framework", Academy of Management Journal, Vol. 61 No. 5, pp. 2000-2019.

Lin, C.H. and Sanders, K. (2017), "HRM and innovation: a multi-level organizational learning perspective", Human Resource Management Journal, Vol. 27 No. 2, pp. 300-317.

Wei, L.Q. and Lau, C.M. (2010), "High performance work systems and performance: the role of adaptive capability", Human Relations, Vol. 63 No. 10, pp. 1487-1511.

Xiao, Z. and Björkman, I. (2006), "High commitment work systems in Chinese organizations: a preliminary measure", Management and Organization Review, Vol. 2 No. 3, pp. 403-422.

\section{Corresponding author}

Nasser Fathi Easa can be contacted at: n.easa@bau.edu.lb 


\section{Appendix}

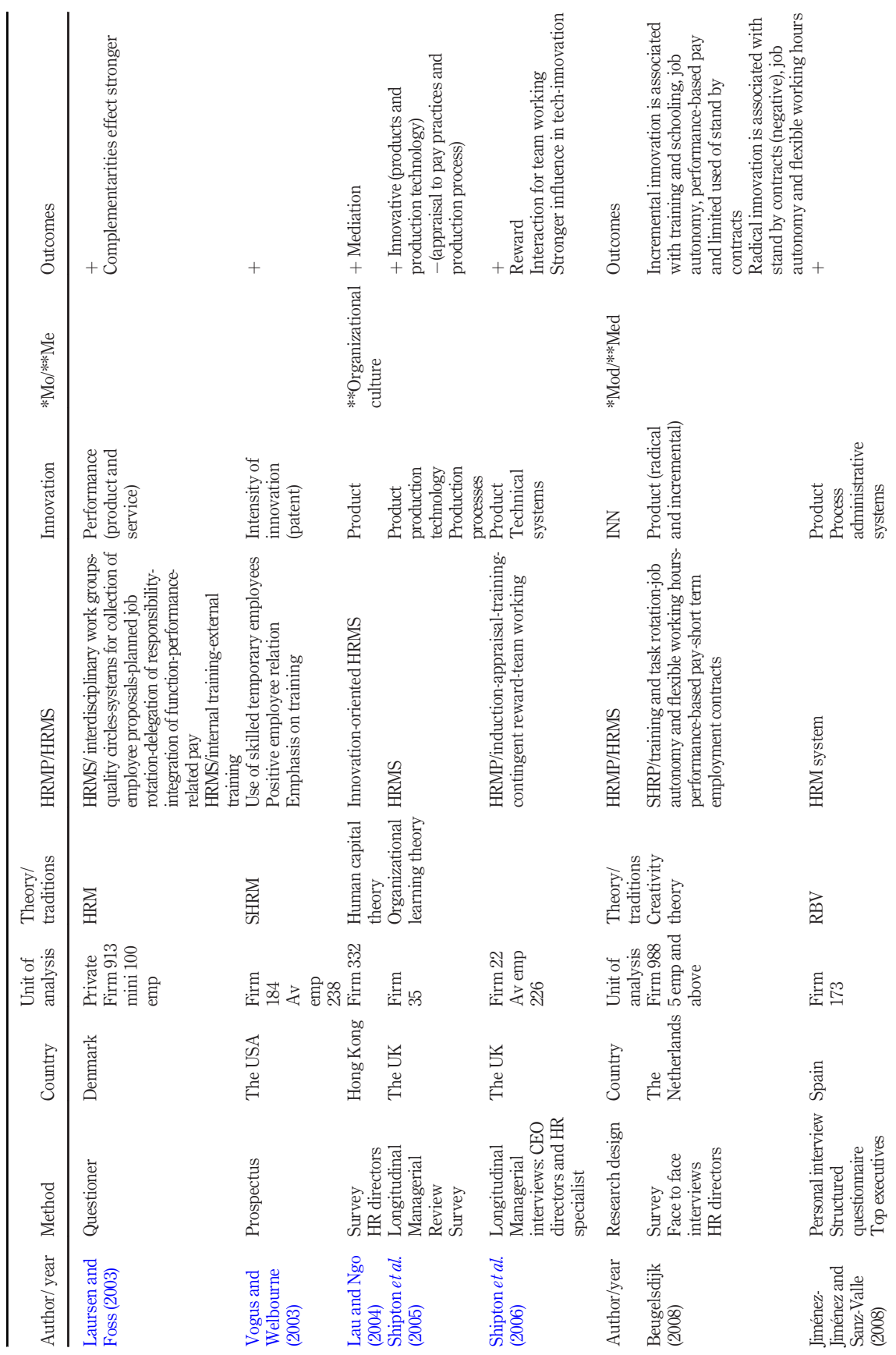

HRM practices and innovation

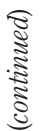

Table AI. Summary of HRMP and innovation publications 


\section{IJDIG \\ 1,1}




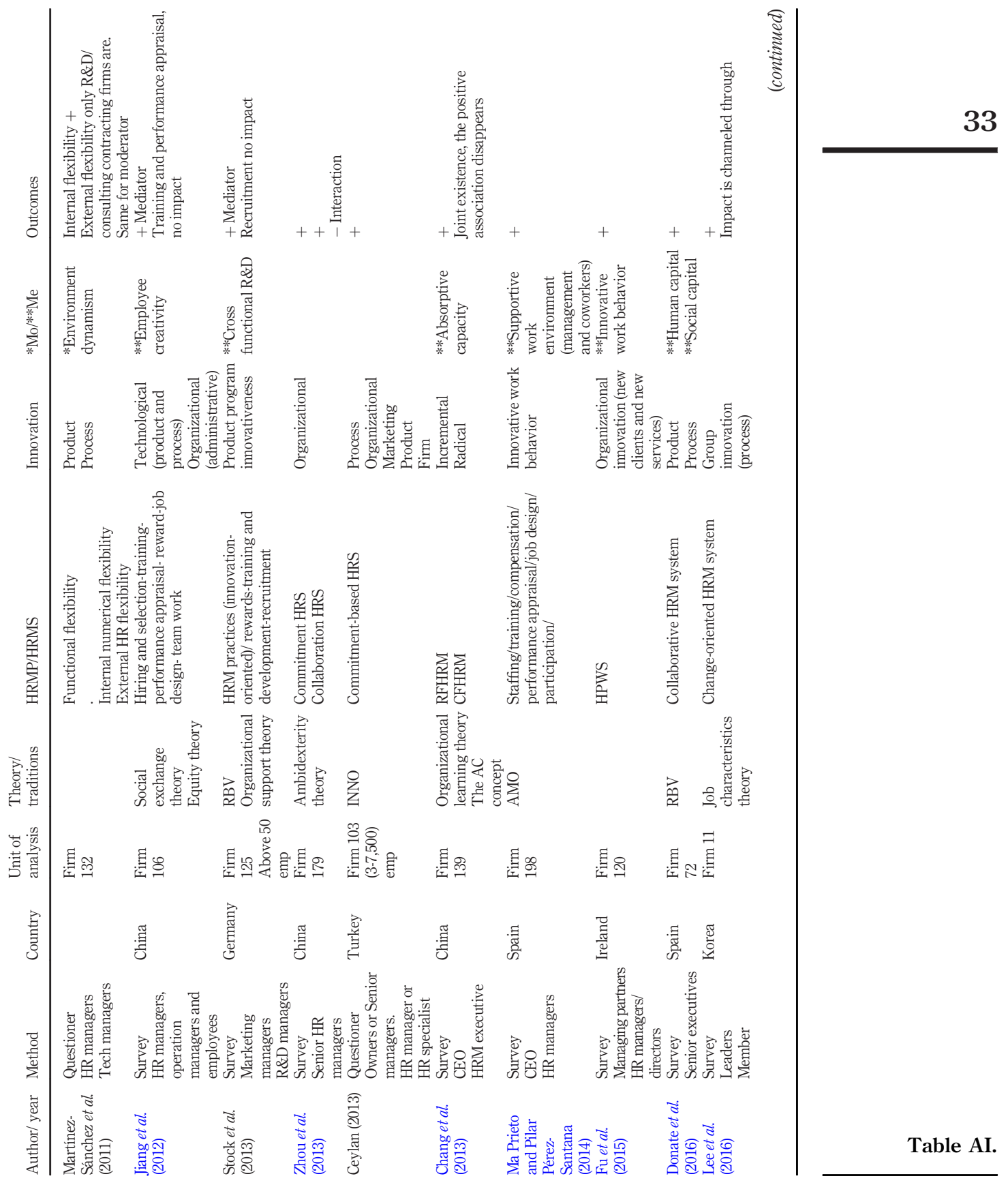




\section{IJDIG \\ 1,1}

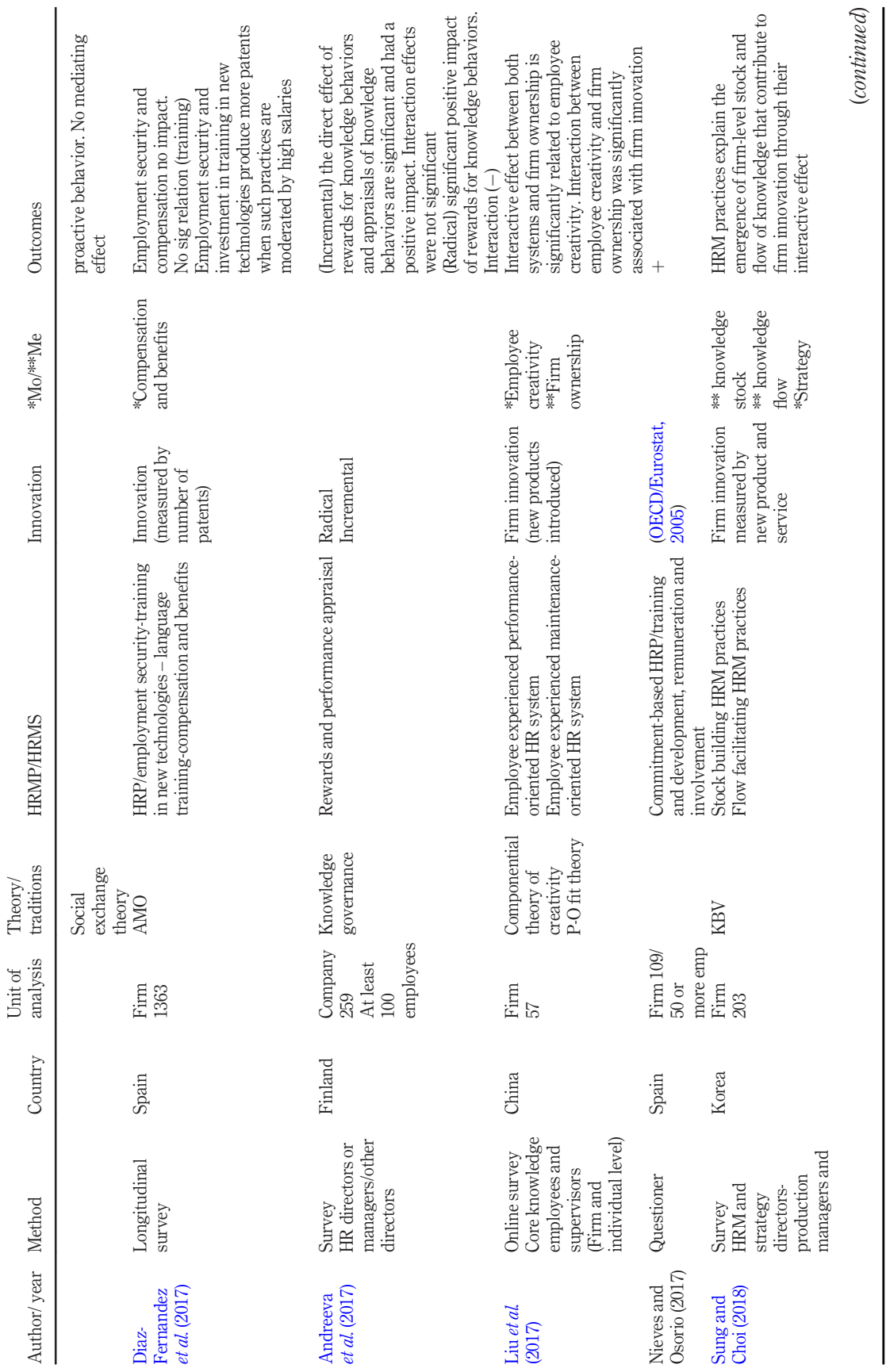

Table AI. 
HRM practices and innovation

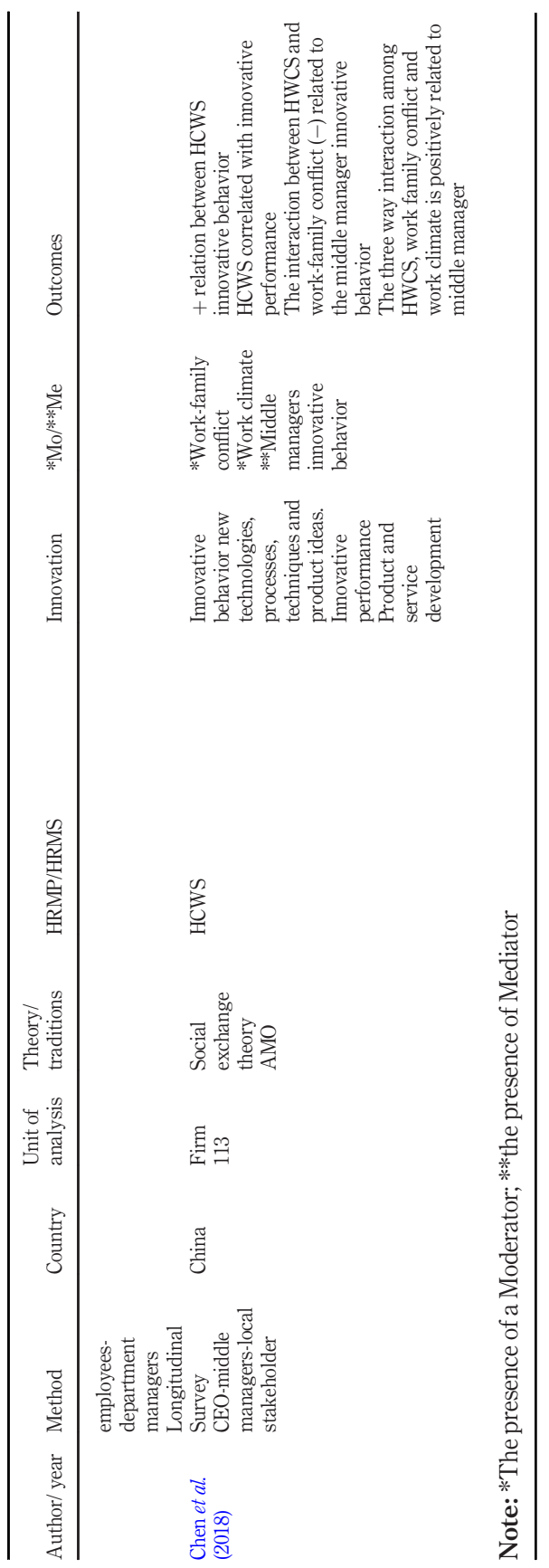

35 